\title{
Giving Voice to Non-traditional Students "Walking" the Narative Mediation Path. An Interpretative Phenomenological Analysis
}

\author{
Dan Florin Stănescu, Elena-Mădălina Iorga, \\ José González Monteagudo and Maria Francesca Freda
}

\section{Introduction}

We live in a knowledge society, where students have to face a series of challenges, such as: the advances in science and technology, the explosion of information available, greater competitiveness, more difficult employability, demographic changes, new forms of (il)literacy, new forms of exclusion, bigger pressures. In order to address these issues, new skills, new attitudes and new tools are required (Baptista et al. 2008).

The societal demand for new abilities, competences and knowledge led not only to a massification of higher education, but also to a need for constant update, nowadays coined as lifelong learning. Starting with the Dearing Report (The National Committee of Inquiry into Higher Education 1997), the importance of widening participation in higher education has been associated with social and economic benefits for individuals, communities and nations. Besides the instrumental benefits (earning more or getting a better job), participation in higher education was also proved to contribute to personal development, identity and social issues such as improvement of familial and community life (Archer et al. 2003).

D.F. Stănescu $(\square) \cdot$ E.-M. Iorga

National University of Political Studies and Public Administration, Bucharest, Romania e-mail: dan.stanescu@ comunicare.ro

E.-M. Iorga

e-mail: iorgaem@yahoo.com

J.G. Monteagudo

Faculty of Education Sciences, University of Sevilla, Seville, Spain

e-mail: monteagu@ hotmail.com

M.F. Freda

University of Naples Federico II, Naples, Italy

e-mail: fmfreda@unina.it

(C) The Author(s) 2015

A. Curaj et al. (eds.), The European Higher Education Area,

DOI 10.1007/978-3-319-20877-0_27 
The profile of the students entering higher education has changed, as their characteristics, their motives, their expectations and demands vary. In this regard, the category of non-traditional, disadvantaged, adult or mature students is experiencing a growth in numbers worldwide. Moving further, this particular group cannot be seen as homogeneous, since the criteria used in defining or describing non-traditional learners are wide and various. For instance, to Correia and Mesquita (2006), non-traditional students are adult people who: dropped out school, may not have academic qualifications, have been apart from the formal academic system for quite a while, do not have previous experience in higher education, and have a low economic and social background. Other studies portray adult learners as having several responsibilities and commitments at work and at home. Therefore, many of them enrol in low frequency courses, due to factors related to limited time for study or lack of flexibility concerning schedules. They are commonly financially independent (Chao et al. 2007; Conrad 1993; Crawford 2004; Rogers 2002; Shankar 2004).

Also referred to as re-entry students, returning students, mature-aged students or new students (Kenner and Weinerman 2011), non-traditional students are usually described as opposed to traditional or conventional ones. Thus, whereas a traditional student is defined as one that enrols immediately after graduating from high school and completes the degree by the age of 24 (Kimbrough and Weaver 1999; Philibert et al. 2008), the non-traditional one is an individual over the age of 24/25 (Ely 1997; Kenner and Weinerman 2011; Powell 2009).

Similarly, the conventional student can be described as one who is 18-24 years old, resides on university grounds, and attends school full time as a product of the support afforded by the parents, economic assistance from grants and scholarships or both (Kimbrough and Weaver 1999; Philibert et al. 2008). On the contrary, adult learners are identified by a number of specific characteristics, some of which include: age, employment, family (in many cases non-traditional students are parents and/or caregivers), and financial responsibilities associated with it (Kimbrough and Weaver 1999). Concurrently, some studies have included characteristics of inadequate representation in their definition of non-traditional students, seen thus as disadvantaged students: gender, race, ethnicity, national origin, education, religion, finances, language, and lack of information, disability, and socio-economic status (Schuetze and Slowey 2002; Taylor and House 2010).

Differences can be identified as well in terms of motivation and goals. From this point of view, if the majority of traditional-age college students enter higher education while being in Erikson's (1968 as cited in Hermon and Davis 2004) “identity versus role diffusion" stage, the non-traditional students (24 years and older) often seek higher education for personal fulfilment, as they are more focused, and have a self-defined goal prior to reentering academic life (Shankar 2004). However, the level of preparedness, which is the student's level of education or the academic background, is weaker in the case of non-traditional students. And the data regarding the completion rates are consistent with this tendency, since less than one in five non-traditional students complete a degree (Lewin 2011). Similar studies report that the drop-out rate in the case of adult learners is much higher than that of 
the traditional student population, as compared to the enrolment rates (Doyle and Gorbunov 2010; Jones 2011). This trend is also common in the U.S., where the latest report of the Advisory Committee on Student Financial Assistance (ACSFA 2013) states that around $73 \%$ of U.S. students enrolled in degree programs are considered non-traditional students. And the increase in enrolments in the case of this particular segment of student population is due to such factors as: the number of laid-off employees who return to college (Kenner and Weinerman 2011; Powell 2009) or the increased educational requirements in the job market (Jones 1996). Additionally, findings suggest that, on average, a person's higher education level is associated with a lower probability of unemployment and a higher earning potential (Doyle and Gorbunov 2010; United States Department of Labor 2012). Although the estimates regarding the exact number of non-traditional learners vary, data so far makes it possible to assume that $40-70 \%$ of the current college/university student population is non-traditional and this population continues to grow, as reported by Powell (2009).

In our research we have adopted the definition offered by Johnston (2011), whereby by 'non-traditional', we mean "students who are under-represented in higher education and whose participation in HE is constrained by structural factors. This would include, for example, students whose family has not been to university before, students from low-income families, students from minority ethnic groups, living in what have traditionally been 'low participation areas', as well as mature age students and students with disabilities" (Johnston 2011, p. 5). For instance, in the RANLHE Project (Johnston 2011, pp. 41-47) five groups of non-traditional students were identified:

(a) Students from low income backgrounds-For these students there are likely to be issues about their cultural capital and habitus, and how they interact with the field of higher education, as well as material constraints on HE access and completion. In this group, transition to HE is still seen by low-income groups as an uncertain process which involved considerable material 'risk' and cost. In fact, financial problems are clearly major influences on retention and drop out for low-income students.

(b) First generation students - Recent research has been interested on 'first generation students', normally defined as students with neither parent having previously completed a degree. In this group of students it is emphasised the importance of 'social capital' and the way it interacts with cultural capital and habitus.

(c) Students from minority ethnic groups, immigrants and refugees-These students have more difficult adaptation to HE, as well as more constraint factors about funding studies. Also they can expect little support from her/his family in choice-making or funding higher education. The language is an important factor when the studies are done in a language different from the native context.

(d) Mature Age Students (including part-timers and students with work and family responsibilities)_-Again such students often come from low income backgrounds and experience some of the problems already identified for people from low income backgrounds, and indeed first generation students. These 
problems are often compounded by additional issues arising from work and family logistics and finance, as well as a lack of confidence in their overall academic, study and IT skills due to a prolonged absence from mainstream study.

(e) Students with disabilities - In response to student disability, some European universities are required to give students with a disability the same opportunities as students without a disability, as well as specific support to increase retention and completion rates in this target group.

Reportedly, up to $45 \%$ of European students are non-traditional learners (Eurostudent IV 2008-11, Social and Economic Conditions of Student Life in EU, Higher Education Information System). The 2010 joint progress report of the European Council and European Commission on the implementation of the Education and Training Work Programme calls for developing and implementing innovative approaches to teaching and learning (OJ/C 2010/C, 117/1), while highlighting the need for "more efforts to support the acquisition of key competences for those at risk of educational underachievement and social exclusion" (OJ/C 2010/C, 117/1). Specifically, the Council's conclusions from May 2010 on the social dimension of education and training, stress the necessity to promote "specific programs for [...] non-traditional learners" (ibid.).

Among the factors identified as interfering with the non-traditional students level of preparedness are: family circumstances, financial and work responsibilities, lack of psychological preparedness for the higher education level work (O'Donnell and Tobbell 2007; Wyatt 2011). Further, degree utility (the value or utility of the degree for the student), goal commitment and career decision-making self-efficacy were linked to non-traditional students' behaviour in terms of persistence decisions (Brown 2002).

Despite the fact that the ratio between traditional and non-traditional students is being inverted, with the adult learners becoming a significant student population, higher education institutions are yet to accept the challenge of thinking beyond the traditional ways of teaching and developing educational programs. We have to admit the fact that some of the challenges are the same both for traditional and for non-traditional students - technological advances, student-centred approaches, active learning etc. It has been stressed that universities can play an important role as change agents in creating supportive learning environments for adult learners (Blair 2010).

However, research so far has mainly focused on academic attainment, considering differences between traditional and non-traditional students in terms of motivations and aptitudes (Kasworm 1990), learning processes (Smith and Pourchot 1998) or classroom instruction and learning styles (Justice and Dornan 2001). Nontraditional-age students are less confident in the effectiveness of their study strategies and their abilities to succeed in college than traditional-age students (Klein 1990). Older students may need assistance to accurately assess their cognitive and management abilities.

Nontraditional-age students reported more frequent use of two higher level cognitive study strategies: hyperprocessing and generation of constructive 
information. Hyperprocessing and generation of constructive information represent relatively sophisticated strategies hypothesized to increase comprehension and integration of information (Christopoulos et al. 1987). In contrast to more passive strategies (e.g. duplicative processing), they require assessment of the cognitive task and active selection of a processing strategy. Such strategies are consistent with a comprehension-focused approach to learning in which adults seek to understand course material (Richardson and King 1998).

Although valuable, these findings do not provide sufficient insights related to the academic experiences of non-traditional students. In this respect, researchers have acknowledged the need for a qualitative approach in order to gain a better understanding of non-traditional students and their multiple roles across family, work and school (Luzzo 1993; Merrill and González-Monteagudo 2010).

Terms like "disadvantaged" or "non-traditional" students are increasingly being used to refer to the new, non-conventional populations coming into higher education who might experience some difficulties adapting to the institution or successfully graduating from university. The first problem in studying the academic performance of underachieving students concerns in the difficulty in defining what is meant by the term "underachieving student". Usually, underachievement is seen as a discrepancy between the level of students' performance and his or her academic potential. Reis and McCoach (2000, p. 157) proposed an operational definition of underachieving students: "students who exhibit a severe discrepancy between expected achievement (as measured by standardized achievement test scores or cognitive or intellectual ability assessments) and actual achievement (as measured by class grades and teacher evaluation)".

The definition of disadvantaged students often includes those belonging to a disadvantaged part of society; migrants, students from migrant households, women, working students and disabled students. It is common to include this category of students in the wider typology of those who are defined as "non-traditional learners" (OJ/C 2010/C, 135/02). These students, besides their disadvantage, may wrestle with several other issues such as, for example, starting their studies later than the average, or being first-generation students enrolled on a full-time basis (Miller and Lu 2003). Despite the differences, the two separate conditions of 'disadvantaged' and 'non-traditional' students share some similarities (Merrill and González-Monteagudo 2010). Moreover, in both categories, students are exposed to the risk of achieving their goals at a later stage in their university career, facing, as a consequence, the risk of dropping out (Choy 2002; Metzner and Bean 1987).

In this context, the INSTALL project promoted inclusive education, equity and social cohesion, while preventing university drop-out of disadvantaged students caused by personal, social, cultural or economic circumstances, who need support to fulfil their educational potential, in line with EU Parliament and Council on Key Competences for LL Recommendation (OJ L 394/10). In INSTALL project, disadvantaged factors were measured through academic delay regarding credits to be passed (and then, taking into account constrained factors related to different profiles of NTS, sometimes with students who had two or more constrained factors). 
INSTALL project promoted the acquisition of the key competence of Learning to Learn (L2L) at university level, by developing and implementing an innovative methodology - the Narrative Mediation Path (NMP), targeted at the disadvantaged group of students. The Narrative Mediation Path is based on the psychological concept of mentalization (as the ability to understand oneself or someone else's mental state) to develop and enhance L2L. Mentalization enables individuals to become aware of theirs and others', mental states (thoughts, beliefs, emotions, wishes and motivations) and recognize, elaborate and modulate emotions throughout the learning process. Mentalization was conceptualized as essential to empowering individuals to strategically use cognitive actions related to mental states (interpret, reason, anticipate, remember, codify etc.), effectively communicate and interact with others. Prior research has already linked metacognition, which involves the ability to monitor and regulate the use of cognitive activities to academic performance (Donaldson and Graham 1999; Hofer et al. 1998). The reflexive process has the effect of suspending part of the actions of the person, to rethink the direction of the actions in contextual terms, and change perspective trough a repositioning. Similarly, INSTALL aims at opening "the prison" of continuity of experience, providing participants with the opportunity to look at themselves in the group through a mirror and a prism, so that they can reconstruct their identity as students. It offers a setting to suspend actions and to rethink one's positioning in the context, activating in such a way a reflexive (Freda and Picione 2012).

Although research so far in this area remains scarce, most studies are firstly aimed at conceptualizing the term, also known as mentalizing (which explicitly refers to the action as such) or reflective function, since there are a series of other constructs that it overlaps with. Allen (2003) distinguishes between mentalization and empathy, in that empathy is but one facet of mentalizing, whereas Gallese (2001) highlights that empathic responses, originated in the mirror neurons system, imply simulating not only actions, but also others' emotions and sensations. However, mentalizing also involves being "conscious of one's affects, while remaining in the affective state" (Fonagy et al. 2002, p. 96) and perceiving them as meaningful, thus being broader than empathy.

Moving further, mentalization was also associated with psychological mindedness which is "a trait, which has as its core the disposition to reflect upon the meaning and motivation of behaviour, thoughts, and feelings in oneself and others" (Farber 1985, p. 170). But in the case of mentalization, the emphasis is on process not on content, as the goal is to foster the skill in mentalizing and not particularly minding the mental content that results from exercising the skill explicitly (Allen 2003). While one can equally mentalize about past and future, mindfulness is strictly present-centred. Further, whereas mentalizing is a reflective process, mindfulness remains pre-reflective, in so far as it refers to experiencing reality in a perceptual and non-evaluative way (Lakoff and Johnson 2003). Nonetheless, mentalizing is equally a form of imaginative activity, since the mind is in itself imaginative (McGinn 2004; Sartre 2004). Mentalizing, either implicitly or explicitly, involves making sense of behaviour by begetting explanations within creative stories. But mentalizing creatively (Heal 2003) does not express itself exclusively 
linguistically, as long as while trying to be aware of others' mental states, one imaginatively recalls visual and other sensory images as one strives to see, feel, and think from others' perspectives. All the same, effective mentalization requires a grounded imagination that is being imaginative without actually entering the imaginary, neither stimulus bond, nor completely losing touch with reality (Allen and Fonagy 2006). The most important contribution in studying mentalization is that of Fonagy and his colleagues (Bateman and Fonagy 2006; Fonagy 1995; Fonagy et al. 2002). They take a step further and define mentalizing taking into account two modes of experiencing: the psychic equivalence mode, which highlights the distinction between inner and outer, fantasy and reality, symbol and symbolized, broadly speaking between the mind and the world, respectively the pretend mode which cuts loose from reality. Conversely, the mentalizing mode is situated in between these two modes. It implicitly or explicitly entails awareness of the mind's intentionality or aboutness, since a mental state is a particular perspective or takes on a given reality. Shortly, while mentalizing, the mind is decoupled from reality while remaining anchored to it (Leslie 1987).

Of course, the most recurrent definition of mentalization has its roots in the philosophy of mind (as cited in Allen 2003; Dennett 1987) and sees it as "a form of mostly preconscious imaginative mental activity, namely, perceiving and interpreting human behaviour in terms of intentional mental states (e.g., needs, desires, feelings, beliefs, goals, purposes, and reasons)" (Allen and Fonagy 2006, p. 54). Likewise, mentalization involves both a self-reflective and an interpersonal component, as it implies seeing yourself from the outside and others from the inside (Allen 2008). Nevertheless, in order to consider others as mental agents (Allen and Fonagy 2006), adopting the intentional stance (Dennett 1987) or the interpersonal interpretative function, is not sufficient. A specific set of cognitive skills that convey the ability to accurately and efficiently attribute mental states to others is also required: perceiving, recognizing, describing, interpreting, inferring, imagining, simulating, remembering, reflecting, and anticipating (Allen 2003).

Scientific evidence demonstrates the key role of narrating as instrumental for the mentalization process, therefore INSTALL defined an innovative methodology based on narration (narrative methodology) to sustain the development of a reflexive/mentalization competence of disadvantaged, non-traditional students' learning experience. INSTALL aimed to developing/enhancing a transversal competence of learning to learn to allow students to build resources in their own environment and turn capacities, knowledge and skills into competences to self-empowerment. That is because, as previous research shows, "during their university career non-traditional students learn to develop and (re/) construct a learning identity in a learning environment, culture and structure which is largely geared towards meeting the needs of younger, 'traditional' undergraduates" (Merill and González-Monteagudo 2010, p. 1).

The current study aimed at gathering first-hand information related to the lived experience of students involved in a specific formative experience within the NMP -Narrative Mediation Path that employed different discursive modules to support 
them in developing their reflexive competence in order to better adjust to the academic life.

The Narrative Mediation Path (NMP) consists in a group training process targeted to disadvantaged students, based on the psychological concept of mentalization, also known as reflexive competence. NMP combines into one methodology four discursive modules or codes: Metaphoric, Iconographic, Written and Bodily. The four codes are implemented in a cycle of six meetings conducted by Narrative Group Trainers (NGTs) who were trained to use this methodology with disadvantaged students.

Through the four codes, the students are presented with the possibility of mentalizing their own personal way of participating in university education and developing a reflexive competence that allows them to learn to learn in a way which is strategic and adaptive within the university context. Although the mentalization/reflexive competence is the final outcome of the training, in each code a reflexive register is activated about the educational experience of the student at different levels of analysis, in relation to different educational situations and according to the different narrative inputs presented to the group as part of the training.

Predominantly, the training is conceptualized as a circular, reflexive process of mentalization about one's own educational experience, starting from an initial synchronic representation of the educational experience (proposed in the first code), passing through a diachronic analysis of a specific university situation, and finally, returning to the synchronic level in which the same experience is reinvestigated in light of the reflexive and meta-reflexive processes previously activated.

\section{Methodology}

The data were analyzed using interpretative phenomenological analysis (IPA). IPA is designed to enable the understanding of the lived experience of the participant, while providing a systematic approach to conducting qualitative research (Smith and Osborn 2003). Below, each case is examined in great detail as an entity before moving to more general claims. Data were collected through five semi-structured interviews, comprising 11 open questions (Table 1).

The participants - five female students enrolled in the INSTALL Narrative Mediation Path training (Romania in October-December 2012) constituted a reasonably homogenous, purposive sample (Smith and Osborn 2003), sufficient to depict a perspective, rather than represent a population. Participants were encouraged to talk as widely as possible about their experience during the NMP training program delivered within the INSTALL project.

The interviews were audio recorded and verbatim transcripts served as raw data for the subsequent analysis, which followed in detail the four-stage process proposed by Smith and Osborn (2003). The analysis began with a close interpretative reading of the first case, where initial responses to the text were annotated in one 
Table 1 Semi-structured interview schedule
- How would you describe/comment on the Install training experience?

- In your opinion which are the strengths and weaknesses of this experience?

- Which modules have been of most use to you? Why?

- Has your participation in the Install course had any specific $( \pm)$ effect?

- Do you think that your university performance has been affected by your participation in the Install course? How?

- Please tell us about an episode relating to your university life, which has occurred recently, when your behaviour, in your opinion, was influenced by what you have learnt during the Install training course

- How did you feel in that situation?

- What do you think that the other people present thought and felt in that situation?

- How did you face that situation?

- Why did you face it in that way?

- Do you think that your thoughts and emotions relating to that situation have changed? Why?

margin. These initial notes were converted into emergent themes at one higher level of abstraction and recorded in the other margin (Smith and Osborn 2003). The researchers then interrogated the themes to make connections between them, which resulted in a table of super-ordinate themes for the first case, including as well the subordinate themes with identifying information. The process was replicated for each of the five cases. Next, patterns were established cross-case and documented in a master table of themes. Finally, the themes were transformed into a narrative account, while the analytic account was supported by verbatim extracts from each participant.

\section{Findings from the Evaluative Study of the NMP Training}

The emerging themes, as identified through the IPA analysis undergone, refer to the relational context of the training (common/shared experiences with other colleagues), the change as such (awareness about changes), and the impact of the NMP both in terms of academic and personal life (post training/secondary effects). Concerning the common/shared experiences theme, participants relate about becoming aware of the fact that their stories are not isolated cases:

"...we have realized that we have common experiences, common feelings and it was nice to talk about various issues related to school, to understand that it is not only me going through such issues... (An, 21)”; “... I have found out a bunch of new and interesting 
things about my colleagues... some things that we have in common and we did not know before... $(\mathrm{Al}, 21)$ "

Similarly, this discovery is associated with a feeling of alleviation:

“...colleagues were in the room and they have written about the same experience... and for me, to see that someone shares the same feelings about something we did together and further shares it at group level was... very pleasant...(C, 21)"; “...in addition, I have seen my colleagues like that... I see that they have passed through the same situations as I did; therefore I am not a freak... as I used to see myself until then... (L, 21)"

Among the changes most frequently described by participants as made aware of (the second emergent theme), there was the management of exam pressure and a better organization of the learning process, as such:

“...management of emotions at exams. I don't know, suddenly I've become more relaxed... (An, 21)"; “...I knew how to distribute my learning time, how to learn. I've realized that if I don't like a matter a marking of 8 will suffice... (An, 21)"; “...I've organized a bit my learning style, but not only this, the life style itself... I've come to trust myself more in doing that... (L, 21)"

As opposed to those who could not specifically name the shifts taken, finding it "difficult to put a finger on what actually changed", some went even further and talked about higher order changes, taking into account the general functioning, irrespective of the context under discussion:

“... it helped me to open myself more... even to organize things... now I don't stress myself that much...(Al, 21)"; “...I've realized that life is beautiful and not so stressful... it helped me see that I am a normal person and I don't need to worry for everything... (Al, 21)"; “... we were able to share our feelings without being ashamed or afraid... I found myself making plans, setting objectives for the next week, next month, even for the next year...(L, 21)"; “.... it helped me see myself in another way... to realize what I am doing and how I am doing it...(Lo, 21)"

Finally, when it came to listing the effects of the NMP training, accounts suggest that the intervention met its main goal, since improvements in academic results were reported:

"...this is the first year without any reexamination (C, 21)"; "this time I didn't have problems with exams (L, 21)"; "this semester I managed to get higher marks than before, especially for interim projects... I become keener to take part in those projects (La, 21)."

Further, the NMP meetings seem to have impacted the attending students on a more general level, improving their availability to take part of activities other than university related, doubled by a boost in motivation and self-confidence:

"...this year I was involved in a lot of activities... until the third year is like I did not exist at all, and now I realize that I want to do a lot of things (C, 21)"; "now I am involved in much more activities...I bring new ideas; I get involved in the decision making process (An, 21)"; “. .. it helped me find my intrinsic motivation... a wish to do things (L, 21)"; “...I feel more self-confident... that I can do things... that's all about... doing stuff (L, 21)" 


\section{Discussions and Conclusions}

Interestingly for policy making, the participants' accounts described a beneficial change due to a relatively simple and gradually intrusive intervention (NMP). Although results cannot always be supported with specific behaviours, all participants reported felling different. The change in the meanings attached to their university life involved a closer sense of social connectedness and a reduced sense of an alienated, isolated, and vulnerable self in the face of the academic challenges faced. Both the participants' sense of self and sense of others were central to their accounts of the experience within the NMP training, as the discursive modules used during the meetings seemed to have touched deeper psychic energies:

after an INSTALL meeting you arrive at home and you say to yourself - I have to think now...I have to reflect. Why am I here? What did I do with my life?... It makes you think at certain things related to your life, your decisions (An, 21).

As it was stated before, the evolution of society and the labour market has led to greater uncertainty for everyone, and for some there is the risk of intolerable situations of exclusion. To cope with these new scenarios, not only do individuals need large and flexible cognitive maps, but also the tools to develop these maps, to extend them and reorganise them continuously throughout their lifetime.

Therefore, learning to learn, defined as the ability to pursue and persist in learning, to organise one's own learning, including the effective management of time and information, both individually and in groups, represent one of the most important competence recognised by the European Union as being crucial in facilitating adaptation to new contexts and promoting inclusion in the world of education and work. This competence includes awareness of one's learning processes and needs, identifying available opportunities, and the ability to overcome obstacles in order to learn successfully. Learning to learn requires learners to build on prior learning and life experiences in order to use and apply knowledge and skills in a variety of contexts, such as at home, at work, in education and training.

The proposed methodology (NMP) assumes that in order to develop such a competence in studying it is necessary for students to activate a process of mentalization of their own educative path (Allen and Fonagy 2006; Fonagy et al. 2002; Fonagy and Target 1997), that is, a process aimed at understanding the reasons for one's own and others behaviours in order to act in the university context in a way which is instrumental to achieving academic success. In other words, the mentalization/reflective function allows the learning individual to see and recognise him or herself while acting, and it combines the emotional, cognitive and social dimensions which go across the educational experience, in order to give them a strategically direction (Esposito and Freda 2014). Furthermore, mentalization allows a person to recognise, elaborate on, and regulate their mental states (e.g., emotions, intentions, desires, beliefs etc.) which underlie the learning process (Allen and Fonagy 2006; Fonagy and Target 1997). In this sense, the student can 
activate a reflective process of mentalization about what and why he or she learns so that the student can gain a new and more functional direction to their academic performance.

Given the fact that the segment of disadvantaged non-traditional students is increasing, the NMP might represent a valuable method for developing the $\mathrm{L} 2 \mathrm{~L}$ competence by increasing the reflective function, although it is not suitable to reach larger segments of student cohort (the maximum number of students recommended for the NMP training is 20). This information could also serve as a framework for enriching the knowledge of those who are engaging in social inclusion and student integration program development.

Some key issues about policies and practice to increase retention and support non-traditional and disadvantaged students (Field and Kurantowicz 2014) include the following recommendations: it is necessary to design and implement specific programmes targeting non-traditional and disadvantaged students to minimize drop-out rates and increase completion; the presence of suitable support prior to entry, including information and guidance, preparatory programmes, and visits to universities and induction programmes to integrate new students are highly important; peer group support among students has high positive impact-peer support can benefit students, especially non-traditional students with low cultural capital and strange to university habitus; programmes aimed at staff and service workers to student integration need to be in place; practical support regarding financial support, counselling, child care, specialist study support, including ICT, libraries and learning resources is necessary; the first year of the student experience appears to be particularly important. At the same time, administrative systems can hinder academic success and retention, stressing formal rules and management that could exclude disadvantaged students.

Moreover, in the Council conclusions of 11 May 2010 (Veugelers 2001) on the social dimension of education and training, the Council invited the Member States to:

(a) promote widened access by strengthening financial support schemes, such as student loans and means-tested grants

(b) improve completion rates, by strengthening individualized support, monitoring and mentoring

(c) provide adequate incentives for the mobility of students, particularly from disadvantages backgrounds

(d) promote specific programs for non-traditional entrants.

As it was presented, there is increasing policy attention towards addressing access to higher education, social inclusion, retention, non-traditional student support, with a variety of instruments being considered. Nevertheless, many times these instruments are often still deployed in isolation, not optimally combined in a truly systemic policy perspective. Therefore, policies and practices developed to promote and provide the opportunity to participate successfully in higher education - such as NMP — need to be more sensitive to the diversity of students and to the different structures of institutions. 
Of course, that much more work still needs to be done in terms of fine tuning the measurements and filling data gaps. Nevertheless, current data provide first hand evidence that policies about non-traditional and disadvantaged students will have a better chance of working if they are listened, giving voice to their experiences, expectations and needs.

Open Access This chapter is distributed under the terms of the Creative Commons Attribution Noncommercial License, which permits any noncommercial use, distribution, and reproduction in any medium, provided the original author(s) and source are credited.

\section{References}

Allen, J. G. (2003). Mentalizing. Bulletin of the Menninger Clinic, 67, 87-108.

Allen, J. G. (2008). Mentalizing as a conceptual bridge from psychodynamic to cognitive-behavioral therapy. European Psychotherapy, 8, 103-121.

Allen, J. G., \& Fonagy, P. (2006). Handbook of Mentalization-Based Treatment. Chichester: Wiley.

Archer, L., Hutchings, M., \& Ross, A. (2003). Higher education and social class: Issues of social inclusion. London: Routledge Falmer.

Baptista, A., Bessa, J., Huet, I., \& Tavares, J. (2008). Studying non-traditional adult students' motivation: A research at the university of Aveiro. Paper presented at the Teaching and Learning 2008, Achieving Excellence and Quality in Education.

Bateman, A., \& Fonagy, P. (2006). Mentalization-based treatment for borderline personality disorder: A practical guide. New York: Oxford University Press.

Blair, A. (2010). In from the margins: The essential role of faculty in transforming a professional studies unit into an academic department. Journal of Continuing Higher Education, 58(1), 31-39.

Brown, S. M. (2002). Strategies that contribute to non-traditional/adult student development and persistence. PAACE Journal of Lifelong Learning, 11, 67-76.

Chao, E., DeRocco, E., \& Flynn, M. (2007). Adult learners in higher education: Barriers to success and strategies to improve results. New York: Nova Science Publishers.

Choy, S. (2002). Nontraditional undergraduates: Findings from the condition of education, 2002. http://nces.ed.gov/pubs2002/2002012.pdf

Christopoulos, J. P., Rohwer, W. D. J., \& Thomas, J. (1987). Grade level differences in students' study activities as a function of course characteristics. Contemporary Educational Psychology, $12,303-323$.

Conrad, J. (1993). Educating part-time adult learners in transition. Retrieved from http://www. ericdigests.org/1993/part.htm

Correia, A., \& Mesquita, A. (2006). Novos públicos no ensino superior: Desafios da sociedade do conhecimento. Lisboa: Edições Sílabo.

Crawford, D. L. (2004). The role of aging in adult learning: Implications for instructors in higher education. http://www.newhorizons.org/lifelong/higher_ed/crawford.htm

Dennett, D. C. (1987). The intentional stance. Cambridge, MA: MIT Press.

Donaldson, J. F., \& Graham, S. (1999). A model of college outcomes for adults. Adult Education Quarterly, 50, 24-40.

Doyle, W. R., \& Gorbunov, A. V. (2010). Getting through. Change: The Magazine of Higher Learning, 42(6), 58-60.

Ely, E. E. (1997). The non-traditional student. Iowa: Iowa State University. 
Esposito, G., \& Freda, M. F. (2014). Investigation of the connection between reflective competence and learning to learn. In M. F. Freda (Ed.), INSTALL innovative solution to acquire learning to learn. Operational manual and guidelines for narrative group trainers. Roma: ARACNE Editrice.

Farber, B. A. (1985). The genesis, development and implications of psychological mindedness in psychotherapists. Psychotherapy, 22, 170-177.

Field, J., \& Kurantowicz, E. (2014). Retention and access in higher education. In F. Finnegan, B. Merrill, \& C. Thunborg (Eds.), Student voices on inequalities in European higher education (pp. 163-168). London: Routledge.

Fonagy, P. (1995). Playing with reality: The development of psychic reality and its malfunction in borderline personalities. International Journal of Psycho-Analysis, 76, 39-44.

Fonagy, P., Gergely, G., Jurist, E. J., \& Target, M. (2002). Affect regulation, mentalization and the development of the self. New York, US: Other Press.

Fonagy, P., \& Target, M. (1997). Attachment and reflective function: Their role in self-organization. Development and Psychopathology, 9(4), 679-700.

Freda, M. F., \& Picione, R. D. L. (2012). Relational and organizational value of self-positions. International Journal for Dialogical Science, 6(1), 51-60.

Gallese, V. (2001). The "shared manifold" hypothesis: From mirror neurons to empathy. Journal of Consciousness Studies, 8(5-7), 33-50.

Heal, J. (2003). Mind, reason and imagination. New York: Cambridge University Press.

Hermon, D., \& Davis, G. A. (2004). College student wellness: A comparison between traditionaland non-traditional-age students. Journal of College Counseling, 7, 32-39.

Hofer, B. K., Yu, S. L., \& Pintrich, P. R. (1998). Teaching college students to be self-regulated learners. In D. H. Schunk \& B. J. Zimmerman (Eds.), Self-regulated learning: From teaching to self-reflective practice (pp. 57-85). New York: Guilford.

Johnston, R. (2011). Access and Retention: Experiences of non-traditional Learners in Higher Education Literature Review, Final Extended Version, August 2011 Retrieved from http:// www.dsw.edu.pl/fileadmin/www-ranlhe/files/Literature_Review_upd.pdf

Jones, R. T. (1996). The new workplace and lifelong learning. Community College Journal, 67(2), $21-23$.

Jones, A. (2011). The rising price of inequality advisory committee on student financial assistance. Department of Education, United States of America, Access and Persistence Retrieved from http://www.ed.gov.ACSFA

Justice, E., \& Dornan, T. (2001). Metacognitive differences between traditional-age and non-traditional-age college students. Adult Education Quarterly, 51(3), 236-249.

Kasworm, C. (1990). Adult undergraduates in higher education: A review of past research perspectives. Review of Educational Research, 60(3), 345-372.

Kenner, C., \& Weinerman, J. (2011). Adult learning theory: Applications to non-traditional college students. Journal of College Reading and Learning, 41(2), 87-96.

Kimbrough, D. R., \& Weaver, G. C. (1999). Improving the background knowledge of non-traditional students. Innovative Higher Education, 23(3), 197-219.

Klein, J. D. (1990). An analysis of the motivational characteristics of college reentry students. College Student Journal, 24, 281-286.

Lakoff, G., \& Johnson, M. (2003). Metaphors we live by. Chicago, IL: University of Chicago Press.

Leslie, A. M. (1987). Pretense and representation: The origin of 'theory of mind'. Psychological Review, 94(4), 412-426.

Lewin, T. (2011, September 27). college graduation rates are stagnant. Even as enrollment rises, a study finds. New York Times. Retrieved from http://www.nytimes.com/2011/09/27/education/ 27remediation.html

Luzzo, D. A. (1993). Career decision-making differences between traditional and non-traditional college students. Journal of Career Development, 20(2), 113-119. 
Merrill, B., \& González-Monteagudo, J. (2010). Experiencing undergraduate learning as a non-traditional adult student: A biographical approach. In L. Gómez, \& D. Martí e I. Candel (Eds.), International conference on education, research and innovation 2010 (pp. 5046-5054). Proceedings CD. Valencia: IATED.

McGinn, C. (2004). Mindsight: Image, dream, meaning. Cambridge, MA: Harvard University Press.

Metzner, B. S., \& Bean, J. P. (1987). The estimation of a conceptual model of nontraditional undergraduate student attrition. Research in Higher Education, 27, 15-38.

Miller, M., \& Lu, M. Y. (2003). Serving non-traditional students in e-learning environments: Building successful communities in the virtual campus. Educational Media International, 40, 163-169.

O'Donnell, V. L., \& Tobbell, J. (2007). The transition of adult students to higher education: Legitimate peripheral participation in a community of practice? Adult Education Quarterly, 57 (4), 312-328.

Official Journal of the European Union C 117/01. (6, May 2010). 2010 joint progress report of the Council and the Commission on the implementation of the 'Education and Training 2010 work programme'. http://eur-lex.europa.eu/legal-content/EN/AUTO/?uri=uriserv:OJ.C_\%20.2010. 117.01.0001.01.ENG. doi:10.3000/17252423.C_2010.117.eng.

Official Journal of the European Union C 135/02. (26, May 2010). Council conclusions of 11 May 2010 on the social dimension of education and training. http://eur-lex.europa.eu/legal-content/ EN/AUTO/?uri=uriserv:OJ.C_.2010.135.01.0002.01.ENG. doi:10.3000/17252423.C_2010. 135.eng.

Official Journal of the European Union L 394/10. (30, December 2006). Recommendation of the european parliament and of the council of 18 December 2006 on key competences for lifelong learning.

Philibert, N., Allen, J., \& Elleven, R. (2008). Non-traditional students in community colleges and the model of college outcomes for adults. International Journal of Adult Vocational Education and Technology, 32(8), 582-596.

Powell, D. S. (2009). No more kid stuff: Colleges and universities take a mature approach to serving adult students. Lumina Foundation: Focus.

Reis, S. M., \& McCoach, D. B. (2000). The underachievement of gifted students: What do we know and where to go? Gifted Child Quarterly, 44(3), 152-170. doi:10.1177/ 001698620004400302.

Richardson, J. T. E., \& King, E. (1998). Adult students in higher education: Burden or boon? Journal of Higher Education, 69, 65-88.

Rogers, A. (2002). Teaching adults. Buckingham: Open University Press.

Sartre, J. P. (2004). The imaginary. New York: Routledge.

Schuetze, H. G., \& Slowey, M. (2002). Participation and exclusion: A comparative analysis of non-traditional students and lifelong learners in higher education. Higher Education, 44, 309327.

Shankar, A. D. (2004). Interpreting the narratives of non-traditional students: An exploratory study. Retrieved from http://www.eric.ed.gov/ERICDocs/data/ericdocs2sql/content_storage_ 01/0000019b/80/13/c3/0c.pdf.ed.gov/ERICDocs/data/ericdocs2sq1/content_storage_ 01/0000019b/80/13/c3/0c.pdf

Smith, J. A., \& Osborn, M. (2003). Interpretative phenomenological analysis. In J. A. Smith (Ed.), Qualitative psychology: A practical guide to research methods (pp. 51-80). London: Sage.

Smith, M. C., \& Pourchot, T. (1998). Adult learning and development: Perspectives from educational psychology. Mahwah, N.J: L. Erlbaum Associates.

Taylor, J., \& House, B. (2010). An exploration of identity, motivations and concerns of non-traditional students at different stages of higher education. Psychology Teaching Review, $16(1), 46-57$.

The National Committee of Inquiry into Higher Education. (1997). The dearing report: Higher education in the learning society. London. 
United States Department of Labor. (2012). Employment projections: Education pays. Retrieved from http://www.bls.gov/emp/ep_chart_001.htm

Veugelers, R. (2001). A policy agenda for improving access to higher education in the EU EENEE. Analytical Report No. 9 Prepared for the European Commission.

Wyatt, L. G. (2011). Non-traditional student engagement: Increasing adult student success and retention. The Journal of Continuing Higher Education, 59, 10-11. 